
\title{
Health-related quality of life assessment in people
} with multiple sclerosis and their family caregivers. A multicenter study in Catalonia (Southern Europe)

This article was published in the following Dove Press journal:

Patient Preference and Adherence

27 October 2009

Number of times this article has been viewed

\section{Marta Aymerich' \\ Imma Guillamón ${ }^{2}$ \\ Albert J Jovell ${ }^{3,4}$}

'Medical Sciences Department, University of Girona, Catalonia, Spain; ${ }^{2}$ Catalan Agency for Health Technology Assessment and Research,

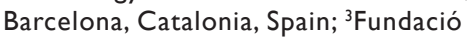
Biblioteca Josep Laporte, Barcelona, Catalonia, Spain; ${ }^{4}$ Autonomous University of Barcelona, Catalonia, Spain
Correspondence: Marta Aymerich School of Medicine, University of Girona, Montilivi Campus (M-20), Girona I707I, Catalonia, Spain Tel + 34972418285

Fax + 34972419617

Email marta.aymerich@udg.edu
Objectives: To measure the health-related quality of life (HRQoL) of multiple sclerosis (MS) patients and their caregivers, and to assess which factors can best describe HRQoL.

Methods: A cross-sectional multicenter study of nine hospitals enrolled MS patients and their caregivers who attended outpatient clinics consecutively. The instruments used were the SF-36 for patients and the SF-12 and GHQ-12 for caregivers. Classification and regression tree analysis was used to analyze the explanatory factors of HRQoL.

Results: A total of 705 patients (mean age 40.4 years, median Expanded Disability Status Scale $2.5,77.8 \%$ with relapsing-remitting MS) and 551 caregivers (mean age 45.4 years) participated in the study. MS patients had significantly lower HRQoL than in the general population (physical SF-36: 39.9; 95\% confidence interval [CI]: 39.1-40.6; mental SF-36: 44.4; 95\% CI: 43.5-45.3). Caregivers also presented lower HRQoL than general population, especially in its mental domain (mental SF-12: 46.4; 95\% CI: 45.5-47.3). Moreover, according to GHQ-12, 27\% of caregivers presented probable psychological distress. Disability and co-morbidity in patients, and co-morbidity and employment status in caregivers, were the most important explanatory factors of their HRQoL.

Conclusions: Not only the HRQoL of patients with MS, but also that of their caregivers, is indeed notably affected. Caregivers' HRQoL is close to population of chronic illness even that the patients sample has a mild clinical severity and that caregiving role is a usual task in the study context.

Keywords: health-related quality of life, multiple sclerosis, caregivers

\section{Background}

Multiple sclerosis (MS) is a chronic progressive neurological disease characterized by central nervous system demyelization and axonal disruption. ${ }^{1}$ Its onset is usually in early adulthood and affects 2.5 million persons worldwide. ${ }^{2}$ MS causes many disabilities such as spastic paresis, ataxia of gait and the extremities, central visual loss, double vision, paresthesia, dysarthria, bladder and sexual disturbances, and fatigue. ${ }^{3}$

The US Institute of Medicine elaborated a report, commissioned by the National Multiple Sclerosis Society, evaluating research needs in the MS field and their perspectives for the future. ${ }^{4}$ According to this report, in spite of the great deal of research effort devoted to this illness, there are still unresolved questions, and one of these is: How can we help persons with MS to adapt to their illness, and live their lives as fully as possible? Our challenge is to meaningfully contribute to the literature on this issue because many factors can condition the quality of life of people with $\mathrm{MS}$, and there is a need to determine what these factors are. Deeper knowledge would 
make it possible to develop and enhance interventions able to maintain or improve these patients' quality of life.

Research in quality of life is part of a movement towards patient-centered care, in which the patient's perspective is taken as the principal reference point, since health-related quality of life (HRQoL) instruments can reveal aspects of illness that are not reflected by standard clinical instruments, and they can measure results that are of major concern to the patient. For the sake of the present study, HRQoL is considered that of perceived overall health, incorporating physical, mental, and social elements. ${ }^{5}$ Some studies emphasize the value of HRQoL to predict changes in disability status over a substantial period of time in patients with MS. ${ }^{6}$ In recent years, different studies have shown the impact of MS on HRQoL, not only in patients, ${ }^{7,8}$ but also in their caregivers. ${ }^{9}$

MS-related disabilities have been reported as probable explanations for this impact. Thus, physical disability, fatigue, chronic pain, sexual disturbance and bladder dysfunction have shown their impact in HRQoL. ${ }^{10-14}$ However, other factors besides disabilities can probably affect HRQoL, and to know amongst them which ones better explain the HRQoL of MS patients could help when setting priorities in treatment programs. Therefore, the aim of the present multicenter study was to measure the HRQoL of MS patients and their family caregivers, as well as to analyze the most important associations between HRQoL and different clinical and sociodemographic characteristics not only of patients, but also of their caregivers, from whose these factors have been poorly studied.

Seven million people inhabit the Catalonia region in the northeast of Spain, which is located in a low-latitude climate zone traditionally considered a low prevalence area for MS. A study of HRQoL in this region is valuable because a rising prevalence of MS has been reported (being as high as 58/100,000 inhabitants) and the disease seems to have a relatively milder clinical severity. ${ }^{15}$ In addition, family social support is more available in Mediterranean countries than in other cultures. ${ }^{16}$ It would, therefore, be also interesting to see whether, given these characteristics, HRQoL of MS patients and their caregivers is similar to the one reported in other regions.

\section{Methods}

A cross-sectional multicenter study was designed, incorporating nine hospitals from Catalonia. The subjects of the study were MS patients and their caregivers who presented consecutively at outpatient clinics in the participating hospitals. The sample size was calculated to be representative for the Catalan MS population bearing in mind data from prevalence studies carried out in the area, ${ }^{15}$ assuming a confidence level of $95 \%$ and an accuracy level that would only tolerate a difference of 0.035 . The sample size was estimated at 638 patients but, assuming a 10\% level of missing data, we aimed to recruit 702 patients and their family caregivers.

The inclusion criteria for patients were as follows: 1) having a definite diagnosis of MS, according to Poser's criteria (relapsing-remitting MS), ${ }^{17}$ or having MS defined clinically or according to laboratory tests, as well as evidence of progressive neurological disability (progressive MS); ${ }^{18}$ and 2) being able to understand the questions on the HRQoL questionnaires. Patients were excluded if they were in an acute phase or a relapse of the illness, were suffering severe illness not related to MS or drug dependency, and/or were taking part in clinical trials. As to the family caregivers, the selection criteria were: 1) that they lived with the patient and took care of him or her; that is, caregiver fulfilled the needs of the patient whatever these needs were (from the minimum ones as helping with the medication, to the maximum ones as providing help with activities of daily living; 2) voluntarily caregiving; and 3 ) being able to understand the questions on the HRQoL questionnaires.

The 36-question Short Form Health Survey (SF-36) was used to assess patients' HRQoL since no specific instrument for MS had been validated in Catalan or Spanish at the time of the study. ${ }^{19}$ The 12-item Short Form Health Survey (SF-12) was used for assessing the family caregivers' HRQoL, ${ }^{20}$ and the short-form General Health Questionnaire (GHQ-12) was used for assessing their psychological distress. ${ }^{21}$ Both the SF-36 and SF-12 22 as well as the GHQ-12 23,24 have been adapted and validated for both Catalan and Spanish languages.

Since the questionnaires had to be answered during the outpatient visit, clinicians considered that questionnaires should take less than ten minutes for a respondent to complete. In addition, taking into account that our underlying hypothesis was that family caregivers would show an affected mental domain in HRQoL, we decided to assess the psychological distress as well (by means of the GHQ-12). Therefore, for the sake of brevity, the SF-12 instead of SF-36 was used for assessing the family caregivers' HRQoL.

The generic instruments for measuring HRQoL - the SF-36 and SF-12 - were designed by the Medical Outcomes Trust, and indicate the subject's state on a scale of 0 (lowest) to 100 (highest). The SF-36 contains 36 questions distributed 
over eight dimensions, covering two areas: functional state and emotional well-being. Although this questionnaire does not generate a global index, it does calculate two summary scales: the physical and mental domains of HRQoL. The SF-12 comprises a subset of 12 questions from the SF-36, including one or two items from each of its eight dimensions. In calculating the mental and physical health summary scales on the SF-36 and SF-12, local population norms (Spanish, in the present paper) were taken into consideration as previously derived. ${ }^{25}$ In norm-based scoring, each scale is scored to have same average (50) and the same standard deviation (10 points). Without referring to norms, it is clear that anytime a scale score is below 50, health status is below average, and each point is one-tenth of a standard deviation. ${ }^{26,27}$ If $95 \%$ confidence intervals (CI) are calculated and they do not include the value of 50, this means that differences between the reference norm (general population) and the study sample are statistically significant.

The GHQ-12 is the brief version (12 questions) of the General Health Questionnaire (60 questions) designed by Goldberg to detect psychological distress in the general population as well as in outpatients and primary care patients. ${ }^{21}$ The GHQ-12 identifies probable psychological distress (although indicating neither the type of distress nor its severity) based on a certain cut-off point which, in this case, was 3 points.

A specific form with clinical and sociodemographic factors was filled in by the neurologist or the nurse during the outpatient visit. These factors comprise the independent variables of the study that are described below.

The study variables used were as follows:

a) As dependent variables, the scores obtained on the HRQoL scales (SF-36 in patients and SF-12 in family caregivers).

b) As independent variables, the different clinical and sociodemographic factors collected. The latter were: age, sex, marital status, number of children, level of studies and employment situation for all subjects, as well as relationship with the patient and length of time sharing living quarters, for the family caregiver. As clinical variables, in the case of the patient, we took into account the type of MS, number of relapses per year, level of physical disability (Kurtzke's Expanded Disability Status Scale [EDSS] score), ${ }^{28}$ year of diagnosis, current treatment, whether they follow rehabilitation therapy, and chronic co-morbidity according to a closed list of chronic illnesses included in the Catalan Health Survey; ${ }^{29}$ in the case of the family caregiver, we recorded chronic morbidity according to the same list used for the patients, psychopharmacological medications taken, whether they had undergone psychotherapy, and the hours spent daily in physically helping the patient.

All of these items were introduced into a database, checking the entries and eliminating possible duplicate cases. For the statistical analysis of the data, we first carried out a descriptive exploration of the sociodemographic, clinical, and HRQoL characteristics of the patients and their family caregivers. The assessment of possible factors explaining the HRQoL of patients and their family caregivers was conducted using multivariate analysis, seeking a model able to explain dependent variables from the SF-36 and SF-12 based on a series of factors or independent variables. This analysis was carried out using classification and regression tree analysis (CART).$^{30}$ By dividing the independent variables into subgroups, this analysis makes it possible to obtain information for selecting, from amongst all of them, the one having the maximum capacity to explain the values of the dependent variable, ie, one that explains the most variance in the dependent variable. The independent variables were broken up into groups with the idea of minimizing intragroup variance and maximizing intergroup variance. In the analysis, the Chi-square test was used and, in order to control for the multiple test comparison, Bonferroni's correction was applied. At the end of this process, a "tree" was obtained, ranking the potential explanatory variables from greatest to least percentage of explanation of the variance of the dependent variable.

The model's validation was carried out by breaking down the database so that it randomly generated a sample including $60 \%$ of the cases, and then estimating accuracy by calculating the proportion of correct classifications that could be obtained by applying this model to the cases in the random sample.

The statistical analysis was conducted with SPSS software (version 15.0; SPSS Inc., Chicago, IL, USA) and Knowledge Seeker 3.10 (Angoss Software, Toronto, ON, Canada).

\section{Results}

During the three years of the study's data-gathering phase, information was obtained on 705 patients with MS and 551 family caregivers from nine hospitals in Catalonia (northeastern Spain). The distribution of number of patients $\left(\mathrm{n}_{\mathrm{p}}\right)$ and caregivers $\left(\mathrm{n}_{\mathrm{c}}\right)$ by center was: Taulí Sabadell $\left(\mathrm{n}_{\mathrm{p}}=33\right.$; $\left.\mathrm{n}_{\mathrm{c}}=33\right)$; Trueta Girona $\left(\mathrm{n}_{\mathrm{p}}=53 ; \mathrm{n}_{\mathrm{c}}=50\right)$; Clínic Barcelona $\left(\mathrm{n}_{\mathrm{p}}=67 ; \mathrm{n}_{\mathrm{c}}=46\right)$; Vall d'Hebron Barcelona $\left(\mathrm{n}_{\mathrm{p}}=198 ; \mathrm{n}_{\mathrm{c}}=120\right)$; Mútua de Terrassa $\left(\mathrm{n}_{\mathrm{p}}=59 ; \mathrm{n}_{\mathrm{c}}=28\right) ; \operatorname{Vic}\left(\mathrm{n}_{\mathrm{p}}=32 ; \mathrm{n}_{\mathrm{c}}=32\right)$; 
Bellvitge Barcelona $\left(\mathrm{n}_{\mathrm{p}}=129 ; \mathrm{n}_{\mathrm{c}}=120\right)$; Germans Trias Badalona $\left(\mathrm{n}_{\mathrm{p}}=49 ; \mathrm{n}_{\mathrm{c}}=49\right)$; and Fundació Esclerosi Múltiple $\left(n_{p}=85 ; n_{c}=73\right)$. There were no statistically significant differences between centers regarding patients' age, gender, EDSS, and duration of MS.

Table 1 presents the sociodemographic characteristics of both patients with MS and their caregivers. As to clinical characteristics, we found that a majority of patients $(77.8 \%)$ suffered relapsing-remitting MS, with an average physical disability (median), according to EDSS criteria, of 2.5, and at least one co-morbid chronic condition (70.8\%). These patients were mainly being treated with Interferon-beta $(62.5 \%)$, and $29 \%$ were in a rehabilitation program. As to their family caregivers, $67.8 \%$ reported suffering from some kind of chronic illness, and $15 \%$ of these family members were taking psychopharmaceutical medication, receiving psychotherapeutic treatment, or both.

The results of the HRQoL assessment of patients with MS, according to the eight dimensions on the SF-36, were lower in all of these dimensions when compared with the normative data for the general population, even at early stages of physical disability measured by EDSS (Table 2). The physical health summary scale (physical HRQoL) and the mental health summary scale (mental HRQoL) of both patients and caregivers are shown in Table 3 and Figure 1. These results also showed that the MS patients had a lower HRQoL than the general population and, as to their family caregivers, we found that they also perceived their HRQoL (according to the SF-12) to be worse than that of the general population, specifically in its mental component. According to the GHQ-12 results, $27 \%$ of this sample met criteria for probable psychological distress (Table 4).

Looking at the results stratified by gender, we found that women had a lower mental HRQoL than men, both in the MS patients sample (43.7; 95\% CI: 42.6-44.8 versus 45.7; 95\% CI: 44.1-47.2) and in that of their family caregivers (44.4; 95\% CI: 43-45.8 versus 48.4; 95\% CI: 47.2-49.6). In addition, the proportion of probable cases of psychological distress amongst women was significantly higher than in men (Table 4). The differences in the physical HRQoL, when examined by gender, were not statistically significant in either of the sample groups.

In the multivariate analysis, a CART model was designed according to each dependent variable (SF-36 and SF-12 physical and mental health summary scales) in order to determine which were the explanatory factors of the HRQoL of patients with MS and their family caregivers. We found that the factors explaining the physical HRQoL in MS patients were the level of physical disability generated by the illness, and chronic co-morbidity (Figure 1). A third factor that explained the level of perceived physical HRQoL, within the group having moderate disability and some co-morbid condition, was the MS treatment they were receiving, with a higher proportion of patients (93\%) having a physical HRQoL lower than the general population among those who were taking no base treatment. The estimated accuracy of this model was $73 \%$. Regarding the mental HRQoL in patients with MS, self-reported anxiety had the most influence on a poor HRQoL (62\%), followed by self-reported depression; amongst those in the group that did not report suffer from anxiety, the type of MS was the second most important explanatory factor, with a primary progressive pattern being related to a better mental HRQoL. The model's estimated accuracy was $61 \%$.

As an explanatory factor of the SF-12 HRQoL physical health summary scale in family caregivers, employment status was generally the most striking; specifically, finding oneself in a situation of long-term illness explained a lower physical HRQoL. This model's estimated accuracy was 58\%. Regarding the SF-12 HRQoL mental health summary scale in family caregivers, the most important explanatory factor for a mental HRQoL lower than that of the general population was self-reporting of suffering from anxiety (Figure 2). Moreover, among those who reported suffering from anxiety, the hours devoted to helping the patient also influenced their HRQoL; the more hours of dedication, the lower the mental HRQoL. Finally, other secondary explanatory factors for mental HRQoL were self-reported depression, or the kind of relationship with the patient; thus, the mental HRQoL was lower in mothers or children. The model's estimated accuracy was $60 \%$.

\section{Discussion}

The present study has shown that MS patients' HRQoL is lower than that of the general population, as results from previous studies in other regions also showed. ${ }^{7,8,31-33} \mathrm{MS}$ not only affects those who suffer from it directly; their caregivers also presented a HRQoL lower than that of the general population, being especially true where the mental HRQoL is concerned. To this we should add that the mental HRQoL of the family caregivers was closer to that of the population with chronic illness or subclinical depression than that of the general population. ${ }^{34,35}$ These results are consistent with the findings of other studies on the impact of caring for an MS patient on psychological well-being. ${ }^{9,36-38}$ It should also be pointed out that a poor caregiver HRQoL finding is indeed 
Table I Sociodemographics and clinical characteristics of the sample

\begin{tabular}{|c|c|c|}
\hline & Patients $n=705$ & Family caregivers $n=55 \mathrm{I}$ \\
\hline Sex (female) & $459(65 \%)$ & $280(50.8 \%)$ \\
\hline Age (years): mean \pm SD (range) & $40.4 \pm 11.6(16-73)$ & $45.4 \pm 12.8(13-78)$ \\
\hline Years living with the patient: mean \pm SD & - & $11.2 \pm 9.7$ \\
\hline Hours/day caring for the patient: mean \pm SD & - & $3.25 \pm 5.7$ \\
\hline \multicolumn{3}{|l|}{ Marital status } \\
\hline Single & $150(21.3 \%)$ & 49 (8.9\%) \\
\hline Separated or divorced & $50(7.1 \%)$ & $9(1.6 \%)$ \\
\hline Married or with partner & $484(68.7 \%)$ & $47 \mathrm{I}(85.5 \%)$ \\
\hline Widowed & $21(3 \%)$ & $22(4 \%)$ \\
\hline \multicolumn{3}{|l|}{ Tie to patient } \\
\hline Spouse or partner & - & $358(65.9 \%)$ \\
\hline Son or daughter & & $44(8.1 \%)$ \\
\hline Mother & & $98(18 \%)$ \\
\hline Father & & $21(3.9 \%)$ \\
\hline Other & & $22(4.1 \%)$ \\
\hline Subjects with children & $463(65.7 \%)$ & $44 \mathrm{I}(80 \%)$ \\
\hline Number of children - Mean (range) & $2(0-6)$ & $2(0-8)$ \\
\hline \multicolumn{3}{|l|}{ Educational level } \\
\hline No school certificate & $5(0.8 \%)$ & II (2\%) \\
\hline Primary school & $319(45.2 \%)$ & $286(52 \%)$ \\
\hline Secondary school & $240(40 \%)$ & $173(31.5 \%)$ \\
\hline University & $137(22.8 \%)$ & 80 (14.5\%) \\
\hline \multicolumn{3}{|l|}{ Employment situation } \\
\hline Self-employed & 59 (8.4\%) & 91 (16.8\%) \\
\hline Works for an employer & $167(23.7 \%)$ & $242(44.6 \%)$ \\
\hline Unemployed & 38 (5.4\%) & 30 (5.5\%) \\
\hline Long-term illness & $236(33.5 \%)$ & $18(3.3 \%)$ \\
\hline Short-term sick leave & 35 (4.9\%) & $6(1.1 \%)$ \\
\hline Housewife & $122(17.3 \%)$ & $36(6.6 \%)$ \\
\hline Student & $20(2.8 \%)$ & $108(19.9 \%)$ \\
\hline Other & $10(1.4 \%)$ & II (2\%) \\
\hline \multicolumn{3}{|l|}{ Housing } \\
\hline Lives alone & $43(6.1 \%)$ & - \\
\hline Institutionalized & $5(0.7 \%)$ & \\
\hline Lives with spouse and/or children & $5 \mathrm{II}(72.8 \%)$ & \\
\hline Lives with parents & $133(18.9 \%)$ & \\
\hline Other & $10(1.4 \%)$ & \\
\hline \multicolumn{3}{|l|}{ MS pattern } \\
\hline Relapsing-remitting & $477(77.8 \%)$ & \\
\hline Primary progressive & $68(11.1 \%)$ & \\
\hline Secondary progressive & 68 (11.1\%) & \\
\hline Disability: median EDSS & 2.5 & \\
\hline \multicolumn{3}{|l|}{ Duration of MS } \\
\hline Mean (SD) & $6.33(5.40)$ & \\
\hline Range & $0-34$ & \\
\hline
\end{tabular}


Table I (Continued)

\begin{tabular}{lll}
\hline & Patients $\mathbf{n}=\mathbf{7 0 5}$ & Family caregivers $\mathbf{n}=\mathbf{5 5}$ I \\
\hline Co-morbidity & & $176(32.2 \%)$ \\
None & $181(29.2 \%)$ & $142(26.0 \%)$ \\
One & $143(23.1 \%)$ & $87(15.9 \%)$ \\
Two & $108(17.5 \%)$ & $56(10.2 \%)$ \\
Three & $83(13.4 \%)$ & $40(7.3 \%)$ \\
Four & $51(8.2 \%)$ & $46(8.4 \%)$ \\
Five or more & $53(8.6 \%)$ & Arthrosis or arthritis $(19.1 \%)$ \\
Most frequent co-morbidity & Anxiety $(25.3 \%)$ & \\
\hline
\end{tabular}

Notes: Patients' missing values: age (6); educational level (4); housing (3); MS pattern (92); disability-EDSS (106); years with MS (88); co-morbidity (86). Family caregivers' missing values: age (10); years living with patient (32); hours/day physically assisting the patient (94); tie to patient (8); subjects with children (4); educational level (I); employment situation (9); co-morbidity (4).

Abbreviations: EDSS, Expanded Disability Status Scale; SD, standard deviation.

more relevant given that in our study we considered any kind of caregiving, including minimal tasks as preparing medication, that our patients sample had a relatively mild clinical severity (median EDSS 2.5), and that caregiving role is a usual task in our culture.

The observed patients' HRQoL scores on the eight SF-36 dimensions were found to be within the range of scores reported in other countries where analogous studies have been carried out, including Canada $(\mathrm{n}=198),{ }^{39}$ England $(\mathrm{n}=929),{ }^{40}$ France $(\mathrm{n}=121),{ }^{41}$ Israel $(\mathrm{n}=214),{ }^{42}$ Italy $(\mathrm{n}=445),{ }^{43}$ Norway $(\mathrm{n}=194),{ }^{44}$ Portugal $(\mathrm{n}=23),{ }^{45}$ The Netherlands $(n=56),{ }^{46}$ and the United States $(n=201) .{ }^{47}$ By SF-36 dimensions, the following ones are the HRQoL score ranges (mean and standard deviation when stated) from the above-mentioned previous studies:
- Physical functioning: 29.2 (29.7)-59.9 (25.9)

- Role limitations - physical: 26.7-60.1 (39.5)

- Bodily pain: 49.2 (7.7)-77.1 (24.4)

- General health: 43.2 (17.8)-59.9 (22.6)

- Vitality: 34.7 (22.2)-53.5 (?)

- Social functioning: 56.5 (30.3)-78.5 (24.2)

- Role limitations - emotional: 46.6-89.7 (25.2)

- Mental health: 55.2 (18.1)-78.6 (15.5)

In addition, upon comparing the HRQoL profiles stratified by level of physical disability (EDSS), as was done in other four studies besides ours, ${ }^{39,42,44,48}$ it can be seen that the profiles are similar. However, although these studies were consistent in showing the difference between the HRQoL of MS patients compared with the general population, none of them, including ours, repeated the results of the Canadian

Table 2 HRQoL of patients with MS, total sample, and stratified by EDSS level

\begin{tabular}{|c|c|c|c|c|c|}
\hline & \multicolumn{5}{|l|}{ Mean (SD) } \\
\hline & $\begin{array}{l}\text { Total sample } \\
(n=705)\end{array}$ & $\begin{array}{l}\text { EDDS }<3 \\
(n=3 \mid 5)\end{array}$ & $\begin{array}{l}\text { EDSS 3-6 } \\
(n=222)\end{array}$ & $\begin{array}{l}\text { EDSS }>6 \\
(n=62)\end{array}$ & $\begin{array}{l}\text { Normative sample } \\
(\mathrm{n}=9151)^{*}\end{array}$ \\
\hline \multicolumn{6}{|l|}{ SF-36 dimension } \\
\hline Physical functioning & $52.4 I(32.16)$ & $74.53(22.98)$ & $43.69(23.87)$ & $8.40(\mid 4.64)$ & $84.7(24.0)$ \\
\hline Role limitations - Physical & $45.86(42.69)$ & $59.02(42.57)$ & $36.66(39.76)$ & 38.71 (38.86) & $83.2(35.2)$ \\
\hline Bodily pain & $69.01(29.08)$ & $71.23(27.76)$ & $64.62(29.65)$ & $65.35(32.54)$ & $79(27.9)$ \\
\hline General health & $49.69(20.28)$ & 55.5 I (20.72) & $43.92(17.88)$ & $43.78(19.55)$ & $68.3(22.3)$ \\
\hline Vitality & $46.49(23.44)$ & $53.67(22.57)$ & $38.97(22.05)$ & $43.10(22.58)$ & $66.9(22.1)$ \\
\hline Social functioning & $71.02(27.82)$ & $78.61(23.76)$ & $66.65(27.74)$ & $56.75(34.84)$ & $90.1(20.0)$ \\
\hline Role limitations - Emotional & $67.87(41.98)$ & $72.93(39.16)$ & $64.34(43.49)$ & $70.97(42.46)$ & $88.6(88.6)$ \\
\hline Mental health & 61.79 (21.32) & $65.08(20.4 I)$ & 59.7। (2I.96) & $60.79(22.36)$ & $73.3(20.1)$ \\
\hline
\end{tabular}

Notes: EDSS categories: EDSS $<3$ (mild; from normal neurological results to minimal disability), EDSS 3-6 (moderate; fair disability but retaining ambulation), EDSS > 6 (severe; from requiring important assistance for ambulation to restricted to chair or bed). As stated in Table I, there were 106 missing values regarding EDSS levels. *From Alonso and colleagues. ${ }^{25}$

Abbreviations: EDSS, Expanded Disability Status Scale; SD, standard deviation. 
Table 3 HRQoL (summary scales) of MS patients and their caregivers

\begin{tabular}{lccccc}
\hline & $\mathbf{n}$ & Mean (SD) & $\mathbf{9 5 \%} \mathbf{C l}$ & Min & Max \\
\hline $\begin{array}{l}\text { Patients } \\
\begin{array}{l}\text { SF-36 Physical health } \\
\text { summary scale }\end{array}\end{array}$ & 696 & $39.85(10.36)$ & $39.08-40.62$ & 14.36 & 63.66 \\
$\begin{array}{l}\text { SF-36 Mental health } \\
\text { summary scale }\end{array}$ & 696 & $44.39(12.02)$ & $43.49-45.28$ & 8.72 & 68.62 \\
$\begin{array}{l}\text { Caregivers } \\
\text { SF-I2 Physical health }\end{array}$ & 522 & $49.63(10.05)$ & $48.77-50.49$ & 18.10 & 66.44 \\
$\begin{array}{l}\text { summary scale } \\
\text { SF-I2 Mental health }\end{array}$ & 522 & $46.4 I(10.66)$ & $45.49-47.32$ & 12.40 & 64.42 \\
summary scale & & & & & \\
\hline
\end{tabular}

Abbreviations: HRQoL, health-related quality of life; $n$, sample size; SD, standard deviation; $\mathrm{Cl}$, confidence interval; Min, minimum value; Max, maximum value.

study, in which very poor HRQoL was found from the lowest levels of physical disability (EDSS $<3$ ). Still, it is worth bearing in mind that the Canadian study, unlike the others, had taking Interferon-beta as one of its exclusion criteria. Actually, a multicenter study in Germany $(\mathrm{n}=1157)$ showed that HRQoL was considerably lower in early stages of MS compared with the general population but was improved, with statistically significant results, after treatment initiation with Interferon-beta. ${ }^{49}$

The male-to-female ratio of patients in our study (1:1.9; derived from Table 1 data) practically coincides with the distribution in our area overall $(1: 2 ; 1: 1.8) \cdot{ }^{15,50}$ Regarding gender distribution of family caregivers, looking at Table 1 , our most striking finding was that they were practically 50:50, despite the fact that the most frequent tie with patients was a spousal relationship (70\%) and the majority of the patients were women (65\%). Therefore, statistically, most of the family caregivers should have been men, but that was not the case; indeed, $93 \%$ of the male patients were cared for by a woman, but not vice-versa, because only $72 \%$ of the women had a male caregiver. These findings agree with other study in southern Europe ${ }^{51}$ and contrast with those of a study of MS patients' families in New Zealand, where most of the caregivers were men, even though in this country the caregiver role was not a traditionally male one, either. ${ }^{52}$

The gender differences in HRQoL found in the present study also appear in the general population. ${ }^{25}$ However, these differences, both in patients and caregivers, were only statistically significant for the mental health domain of the HRQoL. In fact, amongst caregivers, the proportion of psychological distress was higher in women $(29.5 \%)$ than in men (24\%). Such a difference is also found in the general population, although it is less marked (18.9\% in women and $15.8 \%$ in men), and with $9.5 \%$ less possible cases of mental disorder, altogether. ${ }^{23}$

The CART multivariate analysis models used have shown that the potential explanatory factors for a lower HRQoL in patients with MS are the physical disability generated by the illness itself and co-morbidity. Amongst the family caregivers, multivariate models have shown that the mental HRQoL is lower, aside from those who report suffering from anxiety and/or depression, amongst those who spend a greater number of hours with the patient. Although CART models are generally used to "predict", we found them useful in our study because there were many possible factors that could explain HRQoL, and traditional statistical methods are poorly suited for this sort of multiple comparison.

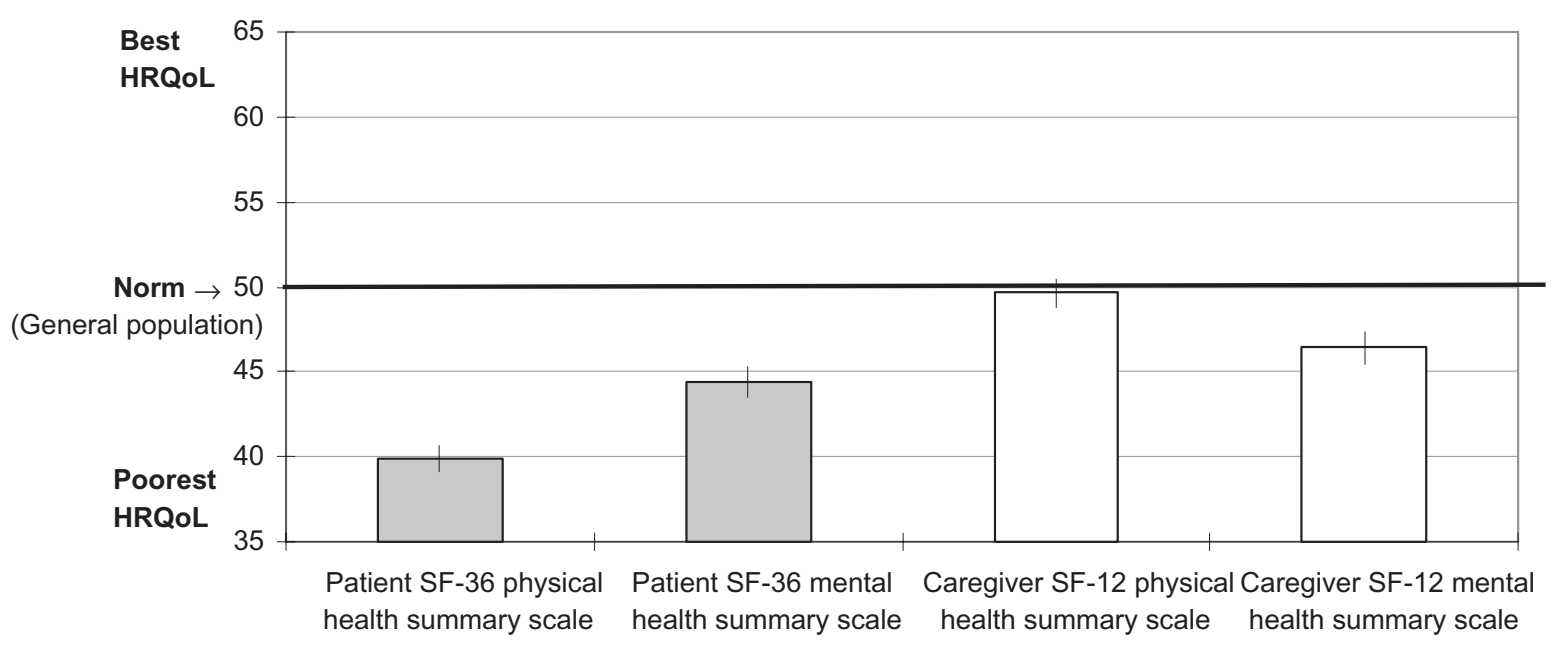

Figure I Interpretation of physical and mental health summary scales of MS patients and their caregivers.

Notes: Vertical lines on each bar represent their $95 \%$ confidence intervals (see Table 3 for exact values). If they are not including the value of the norm, the difference between the study sample and the general population is statistically significant. 
Table 4 Family caregivers' psychological well-being according to GHQ-12

\begin{tabular}{llll}
\hline & Women & Men & Total sample \\
\hline $\begin{array}{l}\text { No psychological } \\
\text { distress }\end{array}$ & $196(70.5 \%)$ & $203(75.7 \%)$ & $399(73.1 \%)$ \\
$\begin{array}{l}\text { Probable psychological } \\
\text { distress }\end{array}$ & $82(29.5 \%)^{*}$ & $65(24.3 \%)$ & $147(26.9 \%)$ \\
\hline
\end{tabular}

Notes: Definition of probable distress: GHQ-12 $\geq 3$; *Statistically significant differences between male and female caregivers.

In addition, complex interactions exist between factors and CART enabled us to avoid making assumptions regarding underlying distribution of the variables and also to overcome the problem of having to adjust for certain variables (eg, for anxiety and depression, which could confuse the association between physical disability and HRQoL in the MS patients, as some authors have suggested). ${ }^{53}$ By this technique we could consider the different subgroups of patients (eg, according to level of physical disability or whether they reported suffer from anxiety or depression) in analyzing these variables' relationship to HRQoL.

Regarding these models, it should be noted that their accuracy was higher than that of the linear multiple regression models that had been used previously. ${ }^{54}$ In the latter, accuracy $\left(\mathrm{R}^{2}\right)$ was only higher than $25 \%$ in the case of physical HRQoL; however, with the CART, accuracy varied from $58 \%$ to $73 \%$. The explanation can be found in the fact that regression implies the existence of a linear relationship, but there are many nonlinear relationships and discontinuities in the present study's factors as other studies also found, ${ }^{42}$ and these are precisely what linear regression fails to catch. Therefore, our study's methodological contribution has been to present the data in such a way that we have been able to detect some of these discontinuities. Moreover, it is much simpler to interpret than the multivariate regression model, bearing in mind that clinicians, patients, and caregivers generally do not think in terms of probability, which is the output regression model yields, but, rather in terms of

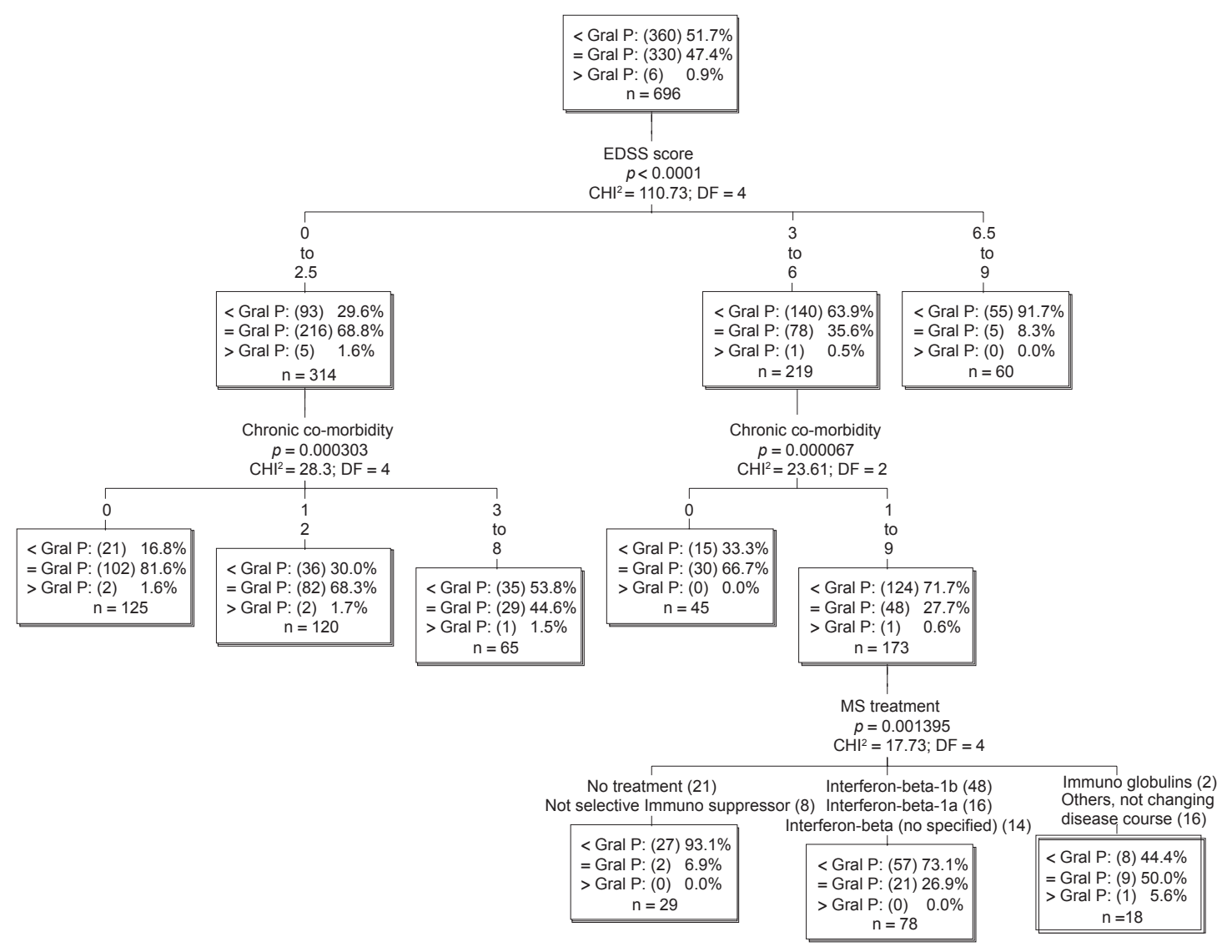

Figure 2 Explanatory factors for the physical domain of HRQoL in patients with MS (SF-36 Physical Health Summary Scale).

Notes: < Gral P, Proportion of patients presenting lower HRQoL (physical domain) than general population; = Gral P, Proportion of patients presenting the same HRQoL (physical domain) than general population; > Gral P, Proportion of patients presenting higher HRQoL (physical domain) than general population; In parentheses, number of patients included in each category.

Abbreviations: DF, degrees of freedom; HRQoL, health-related quality of life. 
categories, such as higher risk or lower risk than general population.

At this point, we should comment on some of the present study's limitations. The first is that, although we obtained our target sample number of patients, we failed to meet our target for family caregivers, because the enrolment process went on for more than three years, and it was difficult to continue the project due to time and resource limitations. However, the sample size achieved $(n=551)$, once we subtract the $5 \%$ of participants with missing values $(n=522)$, means only that the maximum tolerated error - maintaining a confidence level of $95 \%$ - was 0.04 instead of 0.035 . Regarding the patients sample, if we take into account mean duration of MS (6.3 years), the median EDSS score (2.5), and the proportion of patients with secondary progressive MS (11\%), we can think of a sample skewed towards recent disease. However, after three years of data gathering in nine centers that was the real picture we obtained and, actually, a milder clinical severity has been described in this region. ${ }^{15}$ Moreover, our data were within the published HRQoL score ranges. ${ }^{39-47}$
Another limitation involves the instruments we used. First, according to one study, the SF-36 mental health summary scale appear to overestimate mental health in people with MS, ${ }^{55}$ but it could have biased our results towards higher mental HRQoL, meaning that the actual mental HRQoL was still lower, which it wouldn't have change our conclusion, rather strengthen it. Second, also concerning the SF-36, some authors have postulated that, since it is a generic instrument, it is not sensitive enough to measure HRQoL in MS patients because it fails to consider the illness's specific symptoms, and especially, for the baseline effect (incapacity to discriminate amongst degrees of poor HRQoL) of the dimensions of mobility and physical functioning, and the ceiling effect (incapacity to discriminate amongst degrees of better HRQoL) of the dimensions of "pain" and "role limitations due to emotional problems" in patients with MS. ${ }^{56,57}$ However, the SF-36 physical and mental health summary scales have no baseline or ceiling effects. ${ }^{57}$

Finally, on the subject of limitations, it is important to always bear in mind that the associations found do not indicate



Figure 3 Explanatory factors for the mental domain of HRQoL in family caregivers (SF-12 Mental Health Summary Scale).

Notes: < Gral P, Proportion of patients presenting lower HRQoL (mental domain) than general population; = Gral P, Proportion of patients presenting the same HRQoL (mental domain) than general population; > Gral P, Proportion of patients presenting higher HRQoL (mental domain) than general population; In parentheses, number of caregivers included in each category.

Abbreviations: DF, degrees of freedom; HRQoL, health-related quality of life. 
causality, but only statistical association, and that, above all, since this is a cross-sectional study, we cannot determine precisely the direction of this association. However, the approximation through multivariate analysis carried out for the present study serves as a first step in order to then, in the future, confirm findings in a longitudinal study.

\section{Conclusions}

Our results enable us to conclude that in Catalonia (Southern Europe) the HRQoL of patients with MS, as well as their family caregivers, is indeed notably affected, compared with the HRQoL of the general population, and that women (whether patients or family caregivers) are more affected than men insofar as the mental domain of their HRQoL is concerned. Moreover, even in a region where family social support is more usual than in other areas, and therefore, caregiving role is present in most families, caregivers have a HRQoL closer to population with chronic illness than to general population.

This study is the first of its kind in a Catalan population to describe the HRQoL of patients with MS and their caregivers, and to assess the relative importance of individual factors to the physical and mental domains of the HRQoL. CART analysis is useful for explaining the different discontinuities of possible factors explaining the HRQoL of MS patients and their caregivers. According to this analysis, the factors able to explain a lower HRQoL are varied, and although in the case of patients the most relevant ones were clinically related, in the case of their caregivers, social factors as employment status or indirect impact of MS as time spent caring for patients, also explained a poor HRQoL. Looking at all of these factors, the implications to be derived from them are mainly researchoriented: findings yielded by the present study need to be further examined using longitudinal designs, so that we may someday intervene in the factors that impact on HRQoL and, in the field of health services research, study how to better cope with the indirect impact (ie, on family caregivers) of chronic neurodegenerative illness.

\section{Acknowledgments}

Our thanks to all MS patients and their family caregivers who took part in this study. We would also like to thank the professionals who participated in the study: David Genís and Pepi López, Hospital Josep Trueta (Girona); Enric Bufill, Hospital General de Vic; Miquel Aguilar, Maite Olivella and Anna Suñer, Hospital Mútua de Terrassa; Miquel Marco, Consorci Hospitalari Parc Taulí (Sabadell); Domingo Escudero and M. Mataró Hospital Germans Trias i Pujol (Badalona); Josep Ma Grau Veciana, Hospital de Sant Pau (Barcelona);
Xavier Montalbán and Cecília Borràs, Hospital Vall d'Hebron (Barcelona); Francesc X. Graus and Albert Sáez, Hospital Clínic (Barcelona); Txomin Arbizu, Hospital Universitari de Bellvitge; and Ingrid Galán, Montserrat Roig and Carme Oñó Hospital de Dia de la Fundació Esclerosi Múltiple (Barcelona).

This project was funded by the Instituto de Salud Carlos III of the Spanish Government, Fundación MAPFRE, and Fundació La Marató de TV3 (Catalan Telethon Foundation).

\section{References}

1. Neumann H. Molecular mechanisms of axonal damage in inflammatory central nervous system diseases. Curr Opin Neurol. 2003;16(3):267-273.

2. World Health Organization, Multiple Sclerosis International Federation. Atlas: Multiple Sclerosis Resources in the World 2008. Geneva, Switzerland: World Health Organization; 2008. Available from: http:/www.who.int/ mental_health/neurology/en/. Accessed on August 10, 2009.

3. Kesselring J. Symptomatology. In: Kesselring J, editor. Multiple Sclerosis. Cambridge, UK: Cambridge University Press; 1997. p. 71-86.

4. Joy JE, Johnston BR. Multiple Sclerosis. Current Status and Strategies for the Future. Washington DC: National Academy Press; 2001.

5. Fayers PM, Machin D. Quality of life. Assessment, Analysis and Interpretation. West Sussex, UK: John Wiley \& Sons Ltd; 2000.

6. Viischedijk MA, Uitdehaag BM, Klein M, et al. Value of health-related quality of life to predict disability course in multiple sclerosis. Neurology. 2004;63(11):2046-2050.

7. Nortvedt MW, Riise T. The use of quality of life measures in multiple sclerosis research. Mult Scler. 2003;9(1):63-72.

8. Benito-León J, Morales JM, Rivera-Navarro J, Mitchell AJ. A review about the impact of multiple sclerosis on health-related quality of life. Disabil Rehabil. 2003;25(23):1291-1303.

9. McKeown LP, Porter-Armstrong AP, Baxter GD. The needs and experiences of caregivers of individuals with multiple sclerosis: a systematic review. Clin Rehabil. 2003;17(3):234-248.

10. Amato MP, Ponziani G, Rossi F, Liedl CL, Stefanile C, Rossi L. Quality of life in multiple sclerosis: the impact of depression, fatigue and disability. Mult Scler. 2001;7(5):340-344.

11. Janardhan V, Bakshi R. Quality of life in patients with multiple sclerosis: the impact of fatigue and depression. J Neurol Sci. 2002;205(1):51-58.

12. Pittion-Vouyovitch S, Debouverie M, Guillemin F, Vandenberghe N, Anxionnat R, Vespignani H. Fatigue in multiple sclerosis is related to disability, depression and quality of life. J Neurol Sci. 2006;243(1-2):39-45.

13. Kalia LV, O'Connor PW. Severity of chronic pain and its relationship to quality of life in multiple sclerosis. Mult Scler. 2005;11(3):322-327.

14. Nortvedt MW, Riise T, Myhr KM, Landtblom AM, Bakke A, Nyland HI. Reduced quality of life among multiple sclerosis patients with sexual disturbance and bladder dysfunction. Mult Scler. 2001;7(4):231-235.

15. Bufill E, Blesa R, Galan I, Dean G. Prevalence of multiple sclerosis in the region of Osona, Catalonia, northern Spain. J Neurol Neurosurg Psychiatry. 1995;58(5):577-581.

16. Naldini M. The Family in the Mediterranean Welfare States. London, UK: Frank Cass; 2003.

17. Poser CM, Paty DW, Scheinberg LC, et al. New diagnostic criteria for multiple sclerosis: guidelines for research protocols. Ann Neurol. 1983;13(3):227-231.

18. Thompson AJ, Montalban X, Barkhof F, et al. Diagnostic criteria for primary progressive multiple sclerosis: a position paper. Ann Neurol. 2000;47(6):831-835.

19. Ware JE Jr, Gandek B. Overview of the SF-36 Health Survey and the International Quality of Life Assessment (IQOLA) Project. J Clin Epidemiol. 1998;51(11):903-912.

20. Ware J Jr, Kosinski M, Keller SD. A 12-Item Short-Form Health Survey. Construction of scales and preliminary tests of reliability and validity. Med Care. 1996;34(3):220-233. 
21. Goldberg DP, Williams P. A User's Guide to the General Health Questionnaire. Windsor, UK: NFER-Nelson; 1988.

22. Alonso J, Prieto L, Antó JM. La versión española del SF-36 Health Survey (Cuestionario de Salud SF-36): un instrumento para la medida de los resultados clínicos. Med Clin (Barc). 1995;104(20):771-776.

23. Muñoz PE, Vázquez-Barquero JL, Rodríguez F, Pastrana E, Varo J. Adaptación española del General Health Questionnaire (GHQ) de DP Goldberg. Arch Neurobiol. 1979;42:139-158.

24. Rajmil L, Gispert R, Roset M, Muñoz PE, Segura A. Equipo de la Encuesta de Salud de Cataluña. Prevalencia de trastornos mentales en la población general de Cataluña. Gac Sanit. 1998;12(4):153-159.

25. Alonso J, Regidor E, Barrio G, Prieto L, Rodríguez C, De la Fuente L. Valores poblacionales de referencia de la versión española del cuestionario de salud SF-36. Med Clin (Barc). 1998;111(11):410-416.

26. Ware JE Jr. SF- $36^{\circledR}$ Health Survey Update [homepage on the Internet] Lincoln, RI: QualityMetric Inc; updated 2003 Set 11. Available from: http://www.sf-36.org/tools/sf36.shtml. Accessed on August 10, 2009.

27. Vilagut G, Valderas JM, Ferrer M, Garin O, López-García E, Alonso J. Interpretación de los cuestionarios de salud SF-36 y SF-12 en España: components físico y mental. Med Clin (Barc). 2008;130(19): 726-735.

28. Kurtzke JF. Rating neurologic impairment in multiple sclerosis: an expanded disability status scale (EDSS). Neurology. 1983;33(11): 1444-1452.

29. Brugulat P, Séculi E, Medina A, et al. Encuesta de Salud de Cataluña. Percepción de la salud, utilización y satisfacción con los servicios asistenciales desde la perspectiva de los ciudadanos. Med Clin (Barc). 2003;121(Suppl 1):122-127.

30. Breiman L, Friedman JH, Olshen RA, Stone CJ. Classification and Regression Trees. Boca Raton, FL: Chapman and Hall; 1984.

31. Kobelt G, Berg J, Lindgren P, Fredrikson S, Jönsson B. Costs and quality of life of patients with multiple sclerosis in Europe. J Neurol Neurosurg Psychiatry. 2006;77(8):918-926.

32. Gottberg K, Einarsson U, Ytterberg C, et al. Health-related quality of life in a population-based sample of people with multiple sclerosis in Stockholm County. Mult Scler. 2006;12(5):605-612.

33. Spain LA, Tubridy N, Kilpatrick TJ, Adams SJ, Holmes ACN. Illness perception and health-related quality of life in multiple sclerosis. Acta Neurol Scand. 2007;116(5):293-299.

34. Jenkinson C, Layte R. Development and testing of the UK SF-12 (short form health survey). J Health Serv Res Policy. 1997;2(1): $14-18$.

35. Sugar CA, Sturm R, Lee TT, et al. Empirically defined health states for depression from the SF-12. Health Serv Res. 1998;33(4 Pt 1): 911-928.

36. Solari A, Ferrari G, Radice D. A longitudinal survey of self-assessed health trends in a community cohort of people with multiple sclerosis and their significant others. $J$ Neurol Sci. 2006;243(1-2):13-20.

37. Khan F, Pallant J, Brand C. Caregiver strain and factors associated with caregiver self efficacy and quality of life in a community cohort with multiple sclerosis. Disabil Rehabil. 2007;29(16):1241-1250.

38. Alshubaili AF, Ohaeri JU, Awadalla AW, Mabrouk AA. Family caregiver quality of life in multiple sclerosis among Kuwaitis: a controlled study. BMC Health Serv Res. 2008;8:206.

39. The Canadian Burden of illness Study Group. Burden of illness of multiple sclerosis: Part II: Quality of life. Can J Neurol Sci. 1998;25(1): $31-38$.

Patient Preference and Adherence

\section{Publish your work in this journal}

Patient Preference and Adherence is an international, peer-reviewed, open access journal that focusing on the growing importance of patient preference and adherence throughout the therapeutic continuum. Patient satisfaction, acceptability, quality of life, compliance, persistence and their role in developing new therapeutic modalities and compounds to
40. Forbes A, While A, Mathes L, Griffiths P. Health problems and health-related quality of life in people with multiple sclerosis. Clin Rehabil. 2006;20(1):67-78.

41. Vermersch P, de Seze J, Delisse B, Lemaire S, Stojkovic T. Quality of life in multiple sclerosis: influence of interferon- $\beta 1 \mathrm{a}\left(\right.$ Avonex $\left.^{\circledR}\right)$ treatment. Mult Scler. 2002;8(5):377-381.

42. Miller A, Dishon S. Health-related quality of life in multiple sclerosis: The impact of disability, gender and employment status. Qual Life Res. 2006;15(2):259-271.

43. Patti F, Russo P, Pappalardo A, Macchia F, Civalleri L, Paolillo A; for the FAMS study group. Predictors of quality of life among patients with multiple sclerosis: An Italian cross-sectional study. J Neurol Sci. 2007;252(2):121-129.

44. Nortvedt MW, Riise T, Myhr KM, Nyland HI. Quality of life in multiple sclerosis: measuring the disease effects more broadly. Neurology. 1999;53(5):1098-1103.

45. Morales Rde R, Morales Nde M, Rocha FC, Fenelon SB, Pinto Rde M, Silva CH. Qualidade de vida em portadores de esclerose múltipla. Arq Neuropsiquiatr. 2007;65(2B):454-460.

46. Arnoldus JHA, Killestein J, Pfennings LEMA, Jelles B, Uitdehaag BMJ Polman CH. Quality of life during the first 6 months of interferon- $\beta$ treatment in patients with MS. Mult Scler. 2000;6(5):338-342.

47. Pittock SJ, Mayr WT, McClelland RL, et al. Quality of life is favorable for most patients with multiple sclerosis: a population-based cohort study. Arch Neurol. 2004;61(5):679-686.

48. Patti F, Cacopardo M, Palermo F, et al. Health-related quality of life and depression in an Italian sample of multiple sclerosis patients. J Neurol Sci. 2003;211(1-2):55-62.

49. Putzki N, Fischer J, Gottwald K, et al. Quality of life in 1000 patients with early relapsing-remitting multiple sclerosis. Eur J Neurol. 2009;16(6):713-720.

50. Navarro X, Bagunyà J, Galán I, et al. Registro de esclerosis múltiple en Cataluña. Evolución 1988-1993. Rev Neurol. 1994;22:391-396.

51. Rivera-Navarro J, Morales-González JM, Benito-León J; Madrid Demyelinating Diseases Group (GEDMA). Informal caregiving in multiple sclerosis patients: data from the Madrid Demyelinating Disease Group study. Disabil Rehabil. 2003;25(18):1057-1064.

52. Gregory RJ, Disler P. Caregivers of people with multiple sclerosis: a survey in New Zealand. Rehabil Nurs. 1996;21(1):31-37.

53. Janssens AC, van Doorn PA, de Boer JB, et al. Anxiety and depression influence the relation between disability status and quality of life in multiple sclerosis. Mult Scler. 2003;9(4):397-403.

54. Aymerich M. Impacte de l'esclerosi múltiple en la qualitat de vida relacionada amb la salut dels malalts i llurs familiars, i avaluació cost-efectivitat dels nous tractaments per aquesta malaltia. Estudi multicèntric a Catalunya. PhD Thesis. Cerdanyola del Vallès: Universitat Autònoma de Barcelona; 2002.

55. Nortvedt M, Riise T, Myhr KM, Nyland HI. Performance of the SF-36, SF-12, and RAND-36 Summary Scales in a Multiple Sclerosis Population. Med Care. 2000;38(10):1022-1028.

56. Vickrey BG, Hays RD, Genovese BJ, Myers LW, Ellison GW. Comparison of a generic to disease-targeted health-related quality-of-life measures for multiple sclerosis. J Clin Epidemiol. 1997;50(5):557-569.

57. Freeman JA, Hobart JC, Langdon DW, Thompson AJ. Clinical appropriateness: a key factor in outcome measure selection: the 36 item short form health survey in multiple sclerosis. J Neurol Neurosurg Psychiatry. 2000;68(2):150-156.

optimize clinical outcomes for existing disease states are major areas of interest. This journal has been accepted for indexing on PubMed Central. The manuscript management system is completely online and includes a very quick and fair peer-review system. Visit http://www.dovepress.com/ testimonials.php to read real quotes from published authors. 